\title{
LA PERSUASIÓN EN CINCO POETAS GRIEGAS
}

\author{
Maria Esther Conejo
}

\begin{abstract}
RESUMEN
En este artículo, la autora analiza algunos recursos persuasivos utilizados por cinco poetas líricas griegas para expresar una manera distinta de mirar el mundo
\end{abstract}

\begin{abstract}
The author analyzes various persuasive resources used by five lyric Greek female poets to express a different view of the world.
\end{abstract}

La Oratoria, dice George Gennedy (7), puede trazar su historia a los inicios de la civilización, en los intentos de persuasión que se encuentran en la mayor parte de la literatura griega conocida, antes y después de la invención de la retórica formal.

La oratoria griega se inicia con la poesía épica, con Homero ${ }^{1}$. Tiene una excelente continuación, tanto en el debate de ideas como en la expresión de sentimientos y el uso de los argumentos, en la poesía lírica. De ello hay abundantes pruebas en los innumerables estudios que existen sobre los poetas líricos masculinos.

En lo que se refiere a la poesía lírica femenina, no existen tantos estudios, pues no son muchas las poetas que brillaron en la antigüedad griega que se conocen. Y todavía menos son, en comparación con los poetas, las obras que de ellas han sobrevivido hasta nuestros días. Pero aún bajo estas condiciones, su estudio resulta valioso además de interesante por variados motivos: un factor que llama la atención de inmediato al leer a las poetas es la distinta apreciación, interpretación y expresión de valores humanos, considerados a través de la experiencia femenina.

En general, la persuasión de sello femenino puede valorarse desde dos puntos de vista: uno individual en los diferentes poemas o fragmentos de las poetas, otro general y más sutil, pero que permea mucha de la producción lírica griega: la persuasión que nace espontáneamente del amor a la vida y a las cosas bellas de esta, que el hombre griego quiere disfrutar a plenitud.

Entre las poetas antiguas se destaca, por supuesto, en primer lugar, Safo de Lesbos, maestra de arte mélico individual. Sin embargo, también aparecen otras figuras de gran interés, como Erina, Praxila, Corina, así como las poetas de la época helenística Anite, Moero y Nosis. Existen también otras, que mencionaremos a su tiempo. 
Destacan nuestras poetas muchas veces en la selección de los temas que su femenina naturaleza las llevó a abordar; también sobresalen en la manera de mirar el mundo que las rodeaba, o en el retrato subjetivo que de ellas mismas dejaron, así como en el detalle de pequeños rasgos de sus vidas, de su región, de su tiempo, enfatizando en los sentimientos y en sus propias reflexiones y reacciones.

Aunque existen poemas aislados entre los numerosos poetas masculinos que presentan a la mujer en "buena luz", es mucho más común que el género femenino sea retratado como superficial, en tanto interesa sólo su apariencia física o algunos detalles domésticos que para los poetas carecen de importancia. Si leemos además a Semónides de Amorgos $^{2}$ o a Focílides ${ }^{3}$, el retrato es todavía más arbitrario.

Las poetas femeninas, por su parte, nos dejan entrever en sus versos vislumbres de sí mismas y de sus familiares y amigos, de las mujeres de su tiempo y de su región, y destacan principalmente los sentimientos netamente femeninos y sus propias reflexiones y reacciones.

Por supuesto, los unos y las otras, al dar una pintura parcial de la realidad, dejan patente ese contraste entre la apreciación personal de ellos y de ellas, revelando juntos dos aspectos de una misma realidad que a veces se nos escapa: la vida de todos los días en la Grecia Antigua.

Un ejemplo de distinta apreciación personal, lo encontramos en un fragmento de $\mathrm{Safo}^{4}$. Aquí la poeta emite un juicio de valor cuando dice: "Muchos creen que un desfile de caballería es lo más bello de contemplar... Yo creo que lo más bello es contemplar al ser que uno ama".

Para dar fuerza a su argumento, Safo emplea en dos ocasiones el argumento por paradigma. Uno es el mito de Helena; el otro es un ejemplo contemporáneo: la ausencia del ser amado. En el mito de Helena, en la tradición pos-homérica, ésta generalmente es considerada culpable por la guerra de Troya ${ }^{5}$, pero Safo usa este mismo mito para darle fuerza a su argumento: Helena lo dejó todo para seguir su amor por Paris, el principe troyano, y el mismo Homero nunca la culpó. Y si hemos de hablar de culpa, ¿a quién se debería culpar por la guerra: a la mujer que sigue el hombre que ama, o a los hombres que siguen su amor por la guerra? De la misma forma, aunque otros crean que la caballería o una flota de guerra representan la visión más deseable, ella afirma de nuevo: lo más bello es contemplar al ser que se ama. En el contraste, Safo presenta un argumento persuasivo, y lo refuerza con la autoridad del pasado en un claro recurso de persuasión por paradigma.

Continuando con este tema, desarrollado igualmente por poetas masculinos y femeninas, el del amor, encontramos que es tratado por ambos tanto en sus formas más eróticas como en sus formas más sutiles. Safo, ya mencionada arriba, es la poeta que sin lugar a dudas resalta como la máxima exponente de la lírica amorosa de su tiempo. Y no solo eso, es, además, la primera voz femenina en la literatura occidental.

La "Oda a Afrodita" de Safo es un claro ejemplo de persuasión en un poema, y en él, la poeta emplea varias técnicas diferentes. Una de ellas es el paralelo histórico o ejemplo, de acuerdo con Aristóteles ${ }^{7}$ : en los primeros versos, Safo le suplica a Afrodita que no aflija su corazón con pena y angustia, sino que venga a ayudarla, "si alguna vez en el pasado has oído mi voz desde lejos, y le has prestado atención" (versos 5-7). Es clara la intención de la poeta: ella ha invocado a la diosa anteriormente y ha recibido la ayuda que requería; en los versos 13-16, Safo describe en detalle la llegada de la diosa y su deseo de ayudarla "tú, bienaventurada, sonriente la faz inmortal, preguntabas de mi nuevo padecer, de mi nuevo invocar"; el uso 
de la repetición (deeute...deeute) aquí y una tercera vez en los versos 18-19 en que Afrodita, solícitamente pregunta: “'A quien más anhelas que Peitho conduzca a tu amor?" comprueba que Safo quiere reafirmar la idea de que lo que sucedió una vez "debe" repetirse, una clara instancia de persuasión por paradigma.

Existe en el poema otra técnica de persuasión más sutil, más delicada, que surge cuando la poeta trata de subrayar la diferencia, la disparidad, entre ella como ser humano que sufre y suplica, y Afrodita, diosa, bienaventurada e inmortal. Si tomamos como referencia a Aristóteles" ${ }^{8}$, en este punto leeremos: "los hombres se conmueven por las acciones de los que sufren". Tal vez podríamos pensar que Safo, anterior por varios siglos al filósofo, creyó que "los dioses se conmueven por los sufrimientos de los humanos". Lo cierto aquí es que Safo trata de persuadir a Afrodita a que la auxilie en un momento de necesidad, mostrándole abiertamente su sufrimiento, pero al mismo tiempo le recuerda sutilmente el poder y la capacidad que la diosa tiene de ayudarla en esta particular tribulación.

Por un lado, Safo sufre (pépontha) en el verso 15, busca una liberación de sus ansiedades (ek merímnan) en el verso 26, y confiesa que tiene un loco corazón (mainola thumoo) en el verso 18. Por otro lado, y subrayando el contraste, Afrodita es llamada athánata, inmortal, en el primer verso y en el 14 se refiere a ella como athanátoo prosoopoo (su rostro inmortal). Se dirige a la diosa como pótnia, señora y mákaira, bienaventurada, epíteto propio de los dioses, que se refuerza con el de inmortal. Safo la llena con epítetos que indican su poder y superioridad sobre cualquier humano. Pero queda el apelativo dolóploke del verso 2; este epíteto, "urdidora de engaños", es empleado temprano en toda la oda, como adelantándole a la diosa algo sobre la naturaleza de su petición: que emplee sus habilidades para ayudar a Safo. Esta actitud, juguetona por un lado y propiciatoria por el otro, no llega a ser irrespetuosa, pues lo que se dice es cierto y, evidentemente, hace nacer la sonrisa indulgente de la diosa, y, al parecer, también su ayuda.

Todavía Safo emplea una técnica más, la antítesis: Aristóteles ${ }^{9}$ dice que "el estilo antitético es agradable porque los contrarios son fácilmente comprendidos y aún más cuando se colocan uno al lado del otro". En la respuesta de Afrodita a la petición de Safo, la diosa pregunta:

\footnotetext{
¿Quién, oh Safo te desatiende?

Si ahora huye de tí, pronto te perseguirá,

si no acepta dones, luego te los ofrecerá,

si no te ama, pronto te amará,

aún si quererlo.
}

La figura se nos presenta en realidad agradable e ingeniosa, y la antinomia de las ideas es perfecta. A Safo sólo le resta un voto final para cerrar con broche de oro: "cúmpleme cuanto mi alma anhela; tú misma sé mi aliada".

La soledad es otro tema a menudo desarrollado en la poesía griega. Pero en las poetas, tiene rasgos femeninos distintivos; pareciera este un sentimiento originado la mayor parte de las veces por la separación de las mujeres de una familia, o de un grupo de amigas; unas veces por causa del matrimonio, que generalmente interponía espacio entre ellas, otras por la muerte. Este parece ser un indicio de la amistad y del apoyo que se brindaban las mujeres mutuamente entre familiares y amigas. 
En un fragmento de Erina de Telos, la poeta hace una narración de los juegos de niñas de su infancia, de los miedos que tenía a la mormo, de la música de cítara que llegaba del traspatio de su casa, los alimentos que traía la madre y la rueca, instrumento eternamente encontrado en las manos de las mujeres, grandes o pequeñas, libres o esclavas. Los recuerdos de horas felices disfrutadas con su amiga Baucis se truncaron cuando a la amiga le llegó el momento de casarse, momento que fue seguido casi de inmediato por la muerte de ésta. Erina, en su lamento, parece dirigirse a su amiga, con la que evoca los recuerdos con una virtual prosopopeya; pero también interpela a un público invisible, tratando de comunicarle en forma muy convincente el vacío que siente por la ausencia de la amiga, así como por el horror a la muerte.

Se puede apreciar en el fragmento el uso de la antítesis: por una parte se evidencia una vivacidad y una delicadeza al evocar a la amiga, describiendo alegres experiencias compartidas en la niñez y recuerdos felices. Por otro, están los recuerdos más recientes, como el dolor de la separación causado por el matrimonio y después, al morir la amiga, los sentimientos de dolor íntimo, profundo. En esta sección, el "pathos", es evidente y queda expresado en toda su angustiosa realidad y en contraste bien marcado con la tierna emoción de los recuerdos de la infancia.

Varias poetas, sobre todo en la época helenística, escribieron epigramas consistentes en inscripciones de diversa índole como dedicatorias para dioses y diosas, estatuas y retratos de personas, y también epitafios.

Los epitafios escritos por mujeres poetas son, en su mayoría, dedicados a mujeres, pero los hay también para hombres. Aunque la brevedad intrínseca del epitafio no permite mucha expansión, las mujeres poetas tienden "en tono patético" a dar énfasis a los sentimientos de la persona fallecida, de sus familiares - generalmente la madre- y de sus amigas. La más famosa poeta de este tipo de poema grabado es Anite de Tegea, del siglo IV a. C. Entre los 21 epigramas que Meleagro comparó con los lirios purpúreos en su "corona" existen varios epitafios de jóvenes mujeres; en ellos, el pathos destaca, así como el uso frecuente de la prosopopeya.

Existe un epitafio de Anita ${ }^{10}$ que pone en verso la historia de tres vírgenes Milesias, amenazadas por la invasión de los galos, las cuales prefirieron procurarse la muerte que enfrentar la violencia. Las técnicas unidas del marcado patetismo, la prosopopeya al hacer responsable al Ares celta y una acertada selección de epítetos le dan un carácter muy convincente; este epitafio, calificado por un estudioso de "flojo y tradicional", es, me parece, una elocuente exposición que el terror de la guerra y sus violencias causan, no sólo a las tiernas niñas, sino a todas las mujeres y también a muchos hombres en todas partes del mundo. Al leerlo es posible darse cuenta de que los tiempos, en algunos temas humanos, siguen sin cambiar.

No obstante, Anite también escribió epigramas alegres: varios de ellos con el agua como tema central, en medio de los -todavía hoy- polvorientos caminos de Grecia: en uno de ellos, un doble uso de la prosopopeya presenta una imagen de Hermes ${ }^{11}$ presidiendo una fuente que murmura, en una invitación a disfrutar las aguas cristalinas y frías, bajo los árboles y el viento, que el cansado y sediento caminante difícilmente podría rehusar.

Anite es muy versátil y en su poesía se encuentran numerosos epigramas inspirados en temas tan variados y tan inusuales como un saltamontes, un gallo ruidoso o un delfín muerto en la playa. En uno de sus epigramas de animales, presenta un macho cabrío de Dionysos $^{12}$, en una graciosa personificación de tono burlón, muy orgulloso admirando de 
soslayo su rizado mechón de barba, que una vez fue acariciado en las montañas nada menos que por una Náyade.

Otro tipo de poesía es el simposíaco, cultivado con gran éxito -según se nos informapor Praxila de Sición ${ }^{13}$, alrededor de 451 a. C., por el que fue conocida y admirada. En uno de sus fragmentos se destaca su visión realista de la vida y una clara intención didáctica y persuasiva: previene muy efectivamente al amigo de las amenazas que acechan, y las compara con escorpiones bajo las piedras, listos para atacar ${ }^{14}$. La metáfora es fuerte y convincente.

Existe otro fragmento de Praxila, de tema mitológico, y dirigido indudablemente a una mujer, en el que emplea la persuasión por paradigma. El problema aquí es que existen dos interpretaciones contradictorias. Una de un erudito, que pone como ejemplo de buenas relaciones a Admeto. La otra, interpretada por una erudita, previene a la joven al aconsejarle, recordando la conducta de Admeto ${ }^{15}$, esposo de la ejemplar Alcestes en el drama de Eurípides, que ame al valiente y evite al cobarde, pues la gratitud de estos es pequeña.

De la producción de Corina, poeta del siglo VI - V, queda poco. Existe un fragmento, el más largo de todos, que tiene importancia por el sesgo femenino que Corina le confiere. Trata de la competencia musical personificada entre los montes Citerón y Helicón ${ }^{16}$, en el cual Corina reinterpreta la historia del salvamento de Zeus recién nacido por parte de su madre Rhea. El tema, tratado antes que Corina por Hesíodo en la Teogonía, es patriarcal por excelencia y marca la transición del poder femenino de Gaia la madre tierra al masculino de su nieto Zeus (que, para reafirmar este carácter masculino del nuevo poder, da nacimiento él solo a la diosa Atenea). Corina toma una parte del mito y lo reinterpreta para su audiencia femenina, dándole énfasis a la acción heroica de Rhea, esa hábil mujer que salva a su hijo sobrepasando en astucia a su también hábil padre, Cronos. Igualmente, al final de la competencia, en el mismo poema, Corina dirige su atención no a las recompensas para el ganador, como era usual en estos temas en los poetas masculinos, sino a los sentimientos personificados de uno y otro contrincante.

En resumen, se ha querido ofrecer una muestra de algunas habilidades persuasivas de unas pocas mujeres poetas de la lírica griega, que, a través de las experiencia de lo femenino, revelan una faceta diferente de la realidad griega. La persuasión y los recursos retóricos que ellas emplean en sus creaciones surgen de estas vivencias femeninas y le prestan particular encanto y fuerza a su manera de vivir, sentir y ver la vida.

\section{Notas}

1. Ver nuestro artículo "La persuasión Homérica, precursora de la retórica". Revista de Filología y Linguiística de la Universidad de Costa Rica, Vol. XI. Nº 1, Enero-Junio 1985.

2. Semónides, Diehl 1.

3. Focílides, Diehl 2.

4. Safo, fr. 4.

5. Ver como ejemplo Alceo, Voigt $42 \dot{\text { yे }} 283$.

6. Safo, Diehl 1, trad. C. Cornelli.

7. Aristóteles, Retórica, 2.20, 2-3.

8. Retórica $2.8,15$

9. Retórica 1410 a 20 y siguientes.

10. Anite, Ant. Pal. XXIII. 
11. Anite, Ant. Pal. XVII.

12. Anite, Ant. Pal. XV.

13. También escribió escolios, ditirambos narrativos, himnos en honor de héroes y dioses.

14. Praxila, PMG, 750.

15. Praxila. PMG, 749.

16. Corina, PMG, 654.

\section{Bibliografia}

Conejo, María Esther. 1985. "La persuasión homérica, precursora de la retórica". Revista de Filología y Lingüística de la Universidad de Costa Rica. XI (1): 31-8.

Lloyd-Jones, H. y P. Parsons. 1983. "Erina de Telos”. Supplementum Hellenisticum. Berlín. 